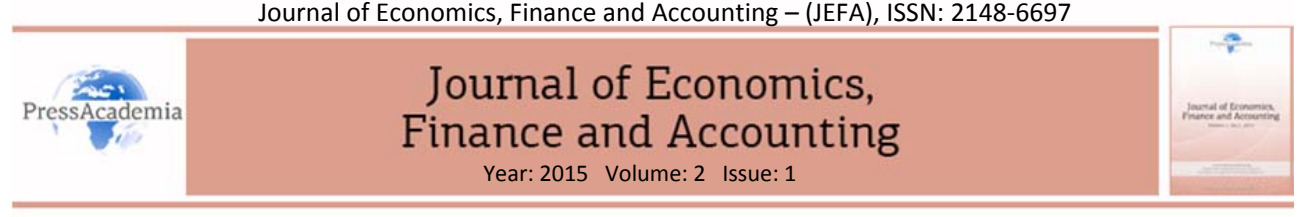

\title{
WEALTH ADDED INDEX (WAI) IN PERFORMANCE MEASUREMENT: AN EMPIRICAL APPLICATION ON BIST 30 INDEX
}

DOI: 10.17261/Pressacademia.201519776

\author{
Ulas Unlu', Oguz Saygin ${ }^{2}$, Ersan Ersoy ${ }^{3}$ \\ ${ }^{1}$ Nevsehir Hacı Bektas Veli University. ulasunlu@gmail.com \\ ${ }^{2}$ Nevsehir Hacı Bektas Veli University. ossaygin@nevsehir.edu.tr \\ ${ }^{3}$ Nevsehir Hacı Bektas Veli University. eersoy1@yahoo.com
}

\section{Keywords}

Wealth Added Index (WAI), performance evaluation, ISE, valuebased management, shareholders value.

JEL Classification G30, L25

\section{ABSTRACT}

In recent years, developments occurring in the financial markets have led to the increasing importance of value-based management approach and the derivation of new performance measures about evaluation. One of these performance measures is Wealth Added Index (WAI) which was developed by the Stern Stewart consulting firm in 2002. WAl performance measure is used to determine which companies provide their shareholders more wealth and this measure is becoming increasingly popular in financial markets. The aim of this study is to determine whether or not shareholder value is created according to Wealth Added Index criteria in BIST 30 Index firms for the year of 2012. The results show that twenty four of the firms create value for shareholders.

\section{PERFORMANS ÖLÇÜMÜNDE SERVET YARATMA ENDEKSI (WAI): BIST 30 içiN AMPIRIK BIR UYGULAMA}

\section{Anahtar Kelimeler Servet yaratma endeksi, performans değerleme, Borsa İstanbul, değere dayalı yönetim, hissedar değeri.}

JEL Sınıflandırması G30, L25

\begin{abstract}
ÖZET
Son yıllarda finansal piyasalarda meydana gelen değişimler, değere dayalı yönetim anlayışının önem kazanmasına neden olmuş ve değerleme konusunda yeni performans ölçütlerinin geliştirilmesine yol açmıştır. Bu performans ölçütlerden biri de 2002 yılında Stern Stewart danışmanlık şirketi tarafından geliştirilen Servet Yaratma Endeksi'dir (Wealth Added Index). Servet Yaratma Endeksi hangi firmaların hissedarlarına daha fazla servet sağladığını belirlemede kullanılmakta olup her geçen gün finansal piyasalarda daha popüler hale gelmektedir. Bu çalışmanın amacı 2012 yılında BIST 30 endeksinde yer alan firmaların Servet Yaratma Endeksine göre hissedar değeri yaratıp yaratmadıklarını tespit etmektir. Çalışmanın sonucunda BIST 30 endeksinde yer alan firmalardan 24 tanesinin hissedarlarına değer yarattığı tespit edilmiştir.
\end{abstract}




\section{GíRiş}

Günümüzde küreselleşme süreciyle birlikte finansal piyasalarda meydana gelen değişimler firma amaçlarını da değiştirmiş ve firmaları hissedar değerini maksimum yapacak yöntemleri kullanmaya yöneltmiştir. Finansal piyasalarda meydana gelen bu değişimler aynı zamanda değer ve değere dayalı yönetim kavramlarını da ön plana çıkarmış bulunmaktadır.

Bu çalışmanın amacı değere dayalı performans ölçüm yöntemlerinden biri olan WAI "Servet Yaratma Endeksi - Wealth Added Index" yöntemini kullanarak BIST 30 endeksinde yer alan firmaların performansını değerlendirmek ve hissedarlarına değer sağlayıp sağlayamadıklarını tespit etmektir. Yapılan literatür taraması neticesinde Türkiye'de bu konuyla ilgili bir çalışmaya rastlanılmadığı, Türkiye'de yapılan çalışmaların genellikle EVA (ekonomik katma değer), MVA (piyasa katma değeri), CVA (nakit katma değer) ve CFROI (yatırımın nakit akım kârıılığı) yöntemleri üzerine odaklandığı görülmüştür.

Değere dayalı yönetim anlayışı firma içerisinde alınacak bütün kararların değer yaratmaya yönelik olarak alınması gerekliliği üzerine odaklanmıştır. Söz konusu bu yaklaşım, yöneticileri ve firma çalışanlarını hissedarlar gibi düşünmeye ve hareket etmeye yönlendirmekte ve geleneksel yönetim davranış ve alışkanlıklarını değiştirip, firma içerisinde değer kavramını ön plana çıkararak onları bu hedefe odaklamaktadır (Ercan ve Ban, 2005:334).

Değer yaratmanın ve ölçmenin temel unsurları şu şekilde sıralanabilir (Chambers, 2009: 24);

Gerçek piyasada, yatırılan sermayenin getirisi yatırılan sermayenin fırsat maliyetinden yüksek olursa değer yaratıldığı anlamına gelir.

$>$ Sermayenin getirisi sermaye maliyetinden ne kadar yüksek olursa o kadar fazla değer yaratılmış olur.

> Beklenen nakit akımlarının bugünkü değerini veya ekonomik kârı maksimize edecek stratejiler seçilmelidir.

$>$ Bir firmanın hisse senedinin borsa değeri, piyasada o firmanın gelecekteki performansına ilişkin beklentilere dayalı olarak oluşan gerçek değere eşittir.

$>$ Hisse senedi sahiplerinin getirileri, firmanın gerçek performansından önce beklentilerdeki değişimlere bağlıdır.

Değere dayalı yönetimin avantaj ve dezavantajlarını ise şöyle özetlemek mümkündür (Ercan ve Ban, 2005:334);

Avantajları;

> Performansın değerlendirilmesinde kullanılabilecek güçlü bir araç olması,

$>$ Değer yaratan ve yaratmayan faaliyetleri belirleyerek en uygun şekilde kaynak sağlamaya yardımcı olması,

$>$ Önemli bir stratejik yönetim amacı olması,

$>$ Yönetimin değer yaratan unsurlara odaklanmasını sağlaması,

$>$ En uygun sermaye yapısını sağlayarak firma değerini pozitif etkilemesi. 


\section{Dezavantajları;}

> Değere dayalı yönetim yapısının ve hesaplamalarının oldukça karmaşık olması,

$>$ Değere dayalı yönetim uygulamasının firma için bir maliyet oluşturması

> İyi uygulanmadığı durumlarda yalnızca teorik olarak kalmaktan öteye gidememesi

Servet Yaratma Endeksi Yöntemi uluslararası finansal piyasalarda sıklıkla kullanılmaktadır. Özellikle de Stern Stewart danışmanlık firması tarafından değişik piyasalarda bu endekse göre firmalar sıralanmakta, hissedarlarına en çok servet sağlayan firmalar ve bu firmaların CEO'ları pek çok ekonomi ve finans dergisine konu olmaktadır. Bu noktadan hareketle çalışmada Türkiye'de henüz uygulama alanı bulamamış olan bu yöntemi BisT 30 endeksinde yer alan firmalara uygulayarak bu konuyla ilgili literatüre katkı sağlamak amaçlanmıştır.

Literatürde, yaratılan değeri ölçmeye yönelik birçok çağdaş finansal performans ölçütü bulunmaktadır. Bunlar arasında; Ekonomik Katma Değer (EVA), Arındırılmış Ekonomik Katma Değer (REVA), Piyasa Katma Değeri (MVA), Hissedar Katma Değeri (SVA), Yatırımın Nakit Akım Kârlılığı (CFROi), Nakit Katma Değer (CVA) ve Değer Yaratma Endeksi (WAI) sayılabilir.

\section{DEĞERE DAYALI YÖNETIM KAPSAMINDA KULLANILAN PERFORMANS ÖLÇÜTLERi}

Çalışmanın bu kısmında, değere dayalı yönetim anlayışı kapsamında literatürde sıklıkla kullanılan performans ölçütleri hakkında bilgi verilmiştir. EVA aslen bir yöntem olmayıp muhasebedeki "artık gelir" kavramına karşılık gelir ve sermaye üzerinde bir takım uyarlamalar yapılarak geliştirilmiştir. EVA artık gelir kavramından çok fazla bir fark göstermemesine karşın pek çok firma tarafından benimsenmiştir (Öztürk, 2004: 351-368).

EVA hem borcun maliyetini hem de özkaynak maliyetini hesaba kattığı için muhasebe kârından ayrılmaktadır. Serbest nakit akımları ile işletmenin cari piyasa değeri arasında oldukça düşük bir ilişki söz konusudur, zaten yatırımların gelecekteki faydalarını göz önüne almamaktadır. EVA yatırımların gelecekteki harcama ve faydalarını da göz önüne aldığı için serbest nakit akımlarına göre cari piyasa değeri ile daha yüksek bir korelasyona sahiptir (Gürbüz ve Ergincan, 2004: 249). EVA’nın hesaplanması için literatürde değişik yaklaşımlar bulunmakla beraber en yaygın olarak aşağıdaki şekilde hesaplanmaktadır (Damodaran, 2002: 864);

$$
E V A=(Y S G-A O S M) x Y S
$$

Burada; YSG, yatırılan sermayenin getirisini, AOSM, ağırlıklı ortalama sermaye maliyetini, YS ise yatırılan sermayeyi ifade etmektedir. Hesaplama sonucu EVA değeri pozitif ise işletmenin katma değer yarattığı, diğer bir deyişle firmanın ortaklarına hissedar değeri yarattığı söylenebilir. Diğer taraftan hesaplanan EVA değerinin negatif olması halinde, işletmenin sermayesinin erozyona uğradığı sonucu ortaya çıkmaktadır.

EVA, elde edilen kârın firma faaliyetlerinde kullanılan sermayenin maliyetini ne ölçüde karşıladığını ve ortaklara ne derecede katma değer yaratıldığını göstermektedir. 
Bu ölçütün tamamlayıcısı olan MVA'nın ise yaratılan katma değerin firmanın piyasa değerine nasıl yansıdığının bir göstergesi olduğu söylenebilir. MVA yöntemi hissedarların servetlerindeki artışı ölçmekle birlikte, firma kaynaklarının ne ölçüde etkin ve verimli olarak değerlendirildiğini de göstermektedir. MVA firmanın yatırımcılardan sağladığı nakit girişi ile yatırımcıların paylarını bugünkü fiyattan elden çıkarması sebebiyle doğan nakit çıkışı arasındaki farkın ölçüsüdür. MVA'yı şu şekilde hesaplamak mümkündür (Stewart and Bennett, 1991);

$$
M V A=\text { Piyasa De ğeri }- \text { Yatırılan Sermaye }
$$

EVA'nın dezavantajlarını ortadan kaldırmak amacıyla REVA yöntemi geliştirilmiştir. REVA yöntemi EVA yönteminin tamamlayıcısı olup, birlikte kullanılabildiği gibi, performans ölçütünü kullanacak işletmenin ölçeğine göre iki yöntemden biri de seçilebilmektedir. En uygun performans ölçütü, yönetim stratejisinin hissedar değerini nasıl etkilediğini, riske göre düzeltilmiş yatırılan sermayenin getirisi olarak ölçen performans ölçütüdür. Bu bağlamda REVA yönteminin üstünlüğü, EVA yöntemi piyasa temelli sermaye ölçütünü varlıkların defter değerini dikkate alarak uygulamaktayken; REVA yöntemi hissedar değerini ölçmekte, piyasa temelli sermaye ölçütünü varlıkların defter değerini değil piyasa değerini dikkate alarak uygulamasından gelmektedir. REVA ise şu şekilde formüle edilebilir (Bacidore vd.,1997; Lee ve Kim, 2009);

$$
\text { REVA = Vergi Sonrası Net Faaliyet Karı - (Piyasa DeğerixAOSM) }
$$

Hissedar katma değeri (SVA) yaklaşımı, tıpkı her varlık gibi, bir firmanın ekonomik değerinin, sermaye maliyetinin tahmin edilen nakit akışından çıkarılmasıyla belirlendiğinin kabul edilmesiyle başlamaktadır. Firmanın beklenen finansal performansı üzerinde sermaye piyasasının yargıları, firmanın piyasa değerine yansımaktadır. Hissedar değeri, hisse senetlerinin piyasa değeri, defter değerini aştığında meydana gelmekte olup, piyasa değerinin temel belirleyicisi ise firmanın kârlı yatırım fırsatlarını yönetebilme yeteneğidir. Hissedar değer analizi, yöneticilerin, firmanın, gelecekteki tüm nakit akışlarının iskonto edilmiş değerini artıran kararlar vermesi halinde, firmanın değerinin de arttığını ifade etmektedir. Yaygın olarak, yatırılan sermayenin getirisi ölçüldüğü zaman, hem firmanın kâr sağlaması yönü ve hem de genel bir kural olarak daha yüksek kârlar elde edilmesi hissedar değerini artırmaktadır. Hissedar değeri, yatırımlardan elde edilen gelirler işletmenin ağırlıklı ortalama sermaye maliyetini aştığı zaman meydana gelmekte ve aksine gelirlerin ağılıklı ortalama sermaye maliyetinden daha düşük olması durumunda ise hissedar değeri yaratılmamaktadır (Sakarya, 2008; 178).

Nakit Katma Değer (CVA), Fredrik Weissenrieder-Anelda Danışmanlık firması tarafından geliştirilmiş bir değer tabanlı performans ölçütü olup nakit akışlarına dayanmaktadır (Ottoson and Weissenrieder, 1996). CVA, EVA'nın en önemli özelliklerinden birisi olan sermaye maliyetini de kapsamaktadır. EVA ile CVA arasındaki temel farklılık, EVA'nın amortismana göre netleştirilmesi, CVA'nın ise amortismana göre netleştirilmemesidir. Bu nedenle CVA savunucularına göre yöntemin en önemli üstünlüğü amortisman yaklaşımlarından etkilenmemesidir (Ertuğrul, 2005: 183). Boston Consulting Group (2000), CVA'nın direkt olarak aşağıdaki gibi hesaplanabileceğini önermiştir; 
CVA

$=$ Faaliyet Nakit Akımlarl - Ekonomik Amortisman

- Brüt Yatırımların Sermaye Maliyeti Tutarı (Brüt Nakit YatırımıxAOSM)

Yatııımın Nakit Akım Kârııı̆̆ı (CFROI), "HOLT Value Associates" adlı danışmanlık firması tarafından geliştirilmiş bir performans ölçüsüdür. Bu yöntem günümüzde pek çok önde gelen danışmanlık firması tarafından dikkate alınmaktadır. CFROI, nakit akışlarını ve paranın zaman değerini dikkate alarak yatırımın beklenen getirisini ölçen bir yöntemdir. CFROI yönteminde hesaplanan değer sermaye maliyeti ile karşılaştııılmaktadır. Bu nedenle bir firmanın değerini yükseltmesi için CFROI ile sermaye maliyeti arasındaki farkı artırması gerekmektedir (Damodaran, 1999:59; Venanzi, 2012: 24).

CFROI'yi hesaplamak için ilk olarak ekonomik amortisman (EA) bulunur, daha sonra ise bulunan değer formülde yerine konarak CFROI değerine ulaşılır (Görke, 2011: 32; Damadoran: 61-62, Chandra, 2011: 814);

$$
\begin{aligned}
& E A=\frac{A O S M}{(1+\text { AOSM })^{n}-1} \times \text { Amortismana Tabi Varlıklar } \\
& \text { CFROI }=\frac{\text { Brüt Nakit Aklşl }- \text { Ekonomik Amortisman }}{\text { Brüt Nakit Yatırım }}
\end{aligned}
$$

Servet Yaratma Endeksi Yöntemi, İngiliz danışmanlık firması Stern Stewart tarafından 2002 yılında geliştirilmiş bir değere dayalı performans ölçütüdür. Servet yaratma endeksi yöntemi, yatırımcıların hisse senetlerinin algılanan riskine dayalı beklentileri üzerinde oluşturulan servetin fazlalığını ölçen yöntem olarak tanımlanmaktadır. Bu performans ölçütü belirli bir zaman periyodunda yatırım yapılan firma sermayesinin piyasa değerindeki artış yoluyla yatııımcılara yönelik nakit akımları, temettü ödemeleri, hisse geri alımları ve yeni hisse senedi ihraç primleri vasıtasıyla yatıımcılara olan toplam servet akışını ölçmektedir. Bu ölçüt yatırımcılara hangi firmaların sermaye yatırımlarının fırsat maliyeti üzerinde bir getiri sağladıklarının belirlenmesinde oldukça fayda sağlamaktadır. Ayrıca, bu ölçüt daha büyük boyutlarda sermaye yatırımları yapıldığında, çok daha tatmin edici düzeyde getiri sağlamaya çalışan üst düzey yöneticilerin belirlenmesine de imkân vermektedir (Wealth Added Scorecard, 2005: 3-5).

Diğer taraftan, Servet Yaratma Endeksi firmaların özkaynaklarından elde edilmesi beklenen getiri için bir ölçüt oluşturmasıyla, firmaya ilgi gösteren kişi ve gruplara önemli bilgiler sunmaktadır. Ölçülen süre boyunca tüm hissedarları kapsaması ve oransal değil tutarsal olarak bir veri sunması, bu performans ölçütünü diğer finansal performans ölçütlerinden ayıran yönüdür. Bu ölçütün, firmanın faaliyet verimliliğinin geliştirilmesi yoluyla vergi sonrası net faaliyet kârının artıııması, sermayenin daha etkin kullanılmasıyla sermaye harcamalarının rasyonel olması, dünya çapında bir sermaye yatıımı analizi ölçütü olarak yapılacak yeni yatıımlarda kullanılacak yeterli düzeyde getiri oranı sağlaması, firmaların fon kaynaklarını optimal sermaye yapısı doğrultusunda yönetmesi gibi yararları bulunmaktadır (Stern and Pigott, 2002: 1-2). 


\section{LITERATÜR}

Bu bölümde değere dayalı performans ölçütleriyle ilgili son yıllarda Türkiye'de yapılan akademik çalışmalar özetlenmiştir. WAI ile ilgili Türkiye'de yapılmış bir çalışmaya rastlanılmamıştır. Şamiloğlu (2004) çalışmasında 1995-2002 döneminde imalat firmaları için, EVA ile artık gelir ve muhasebe kârlarını karşılaştırmıştır. Çalışmada, BisT'de işlem gören imalat sanayi firmalarının hisse başına getirilerinin varyansının \%7.9'unun EVA tarafından açıklandığı bulunmuştur. Kara (2005) çalışmasında piyasa değeri, MVA ve EVA ölçütleri ile geleneksel performans ölçütlerini istatistiksel olarak karşılaştırmış ve geleneksel performans ölçütlerinin bir firmanın piyasa değerindeki değişimi açıklayamadığını tespit etmiştir. Bayrakdaroğlu ve Ünlü (2009) ise çalışmalarında BísT ile NYSE borsalarını EVA ve MVA performans ölçütleri açısından karşılaştırmıştır. Çalışmada elde edilen sonuçlara göre Borsa İstanbul hissedar değeri yaratma konusunda başarılı olamazken, değer yaratmak yerine mevcut sermayeyi tüketmiştir. NYSE ise hissedarlara katma değer yaratmıştır.

Akyüz (2013) çalışmasında EVA ve MVA değerlerini seramik işletmeleri için hesaplamıştır. EVA sonuçlarına göre inceleme dönemlerinin tümünde firmalar ekonomik katma değer yaratamamakla birlikte kayba uğramışlar ve negatif EVA değerleri elde etmişlerdir. Ayrıca çalışmadan elde edilen MVA sonuçları da EVA sonuçlarına benzer olup firmalar negatif MVA değerleri elde etmişlerdir. Yılmaz ve Bastı (2013) çalışmalarında imalat sanayi firmalarının performanslarını EVA ve MVA yöntemlerine göre hesaplamış ve EVA ortalaması en yüksek olan grubun büyük işletmeler, MVA ortalaması en yüksek olan grubun ise küçük işletmeler olduğunu tespit etmiştir. Ünlü ve Saygın (2014) yaptıkları çalışmada Türkiye'de yeni bir yöntem olup daha önce uygulanmamış olan Arındırılmış Ekonomik Katma Değer (REVA) yöntemini 2012 yılında Borsa İstanbul'da işlem gören turizm sektörü firmalarına uygulamışlardır. Çalışmanın sonucuna göre turizm sektörü firmalarının 2012 yılında hissedar değeri yaratamadıkları ve değer yaratmak yerine mevcut sermayelerini tükettikleri tespit edilmiştir. Ünlü (2014) çalışmasında, CFROI ve CVA yöntemlerini, 2012 yılı için Borsa İstanbul'da işlem gören çimento sektörü firmalarına uygulamıştır. Çalışmanın sonucunda çimento sektörü firmalarının etkin bir sermaye yönetimi gösteremedikleri, düzenli bir nakit akışı sağlayamadıkları ve hissedar değeri yaratamadıkları tespit edilmiştir.

\section{VERI YAPISI VE YÖNTEM}

Bu çalışmada uluslararası finansal piyasalarda popüler bir yöntem olan Servet Yaratma Endeksi Yöntemi kullanarak 2012 yılı için BIST 30 endeksinde yer alan firmaların hissedarlarına ne kadar değer yarattıkları araştırılmıştır. 2013 yılında Türkiye ekonomisinde yaşanan sosyal ve ekonomik gelişmelerden dolayı hisse senedi piyasasının volatilitesinde yaşanan artışın yaratacağı olası olumsuz etkiler nedeniyle çalışmada 2012 yılı verileri kullanılmıştır. Çalışma kapsamına sadece 2012 yılı son çeyreğinde BIST 30 endeksinde yer alan firmalar alınmıştır. Bilanço verileri bağımsız denetimden geçmiş 12 aylık veriler olup Kamuyu Aydınlatma Platformu resmi internet sitesinden temin edilmiştir. Özsermaye maliyeti CAPM'in standart formülü kullanılarak $\quad\left[K_{e}=R_{f}+\beta\left(R_{m}-R_{f}\right)\right]$ hesaplanmıştır. Burada piyasanın getirisi $\left(R_{m}\right)$ olarak BIST 30 endeksinin getirisi kullanılmış olup veriler Borsa İstanbul resmi internet sitesinden alınmıştır. Hisse senedi fiyatlarına ilişkin veriler de Borsa İstanbul resmi internet sitesinden alınmıştır. 
Risksiz faiz oranı $\left(R_{f}\right)$ olarak, gösterge niteliği taşıması ve işlem hacminin yoğun olması sebebiyle hazine bonosu yıllık bileşik referans faiz oranı kullanılmıştır. Risksiz faiz oranı verileri Türkiye Cumhuriyet Merkez Bankası resmi internet sitesinden sağlanmıştır. Dolaşımda bulunan hisse senedi sayısı halka açıklık oranı dikkate alınarak hesaplanmış ve veriler bağımsız denetim raporlarından derlenmiştir. Bağımsız denetim raporu verileri ise Kamuyu Aydınlatma Platformu resmi internet sitesinden alınmıştır. Yine ödenen temettüler ve yeni hisse senedi ihraçları ile ilgili veriler Kamuyu Aydınlatma Platformu resmi internet sitesinden elde edilmiştir.

Değere dayalı performans ölçütlerinden biri olan Servet Yaratma Endeksinin hazırlanmasındaki temel kriter, firmaların hissedarlarının ancak yapmış oldukları yatırımın hisse senedi maliyetini aşması durumunda servet elde edebilecekleri fikrinden yola çıkmaktadır. Stern Stewart danışmanlık firması, Temmuz 1996-Temmuz 2001 döneminde 5069 firmayı analiz ederek, bu firmaları hissedarlarına en çok servet sağlayandan başlamak üzere sıralamışlardır. Firma bu yıldan itibaren düzenli olarak Servet Yaratma Endeksi yöntemine göre firmaları değerlemiş ve firmaları servet yaratma derecesine göre sıralamıştır.

Servet yaratma endeksini şu şekilde formüle etmek mümkündür (Stern and Pigott, 2002: 8);

WAI = Piyasa Kapitalizasyonundaki Değişim - Beklenen Getiri + Temettü Ödemeleri - Hisse Senedi ihracı

Piyasa Kapitalizasyonu = Hisse Senedi Sayısı $x$ Hisse Senedinin Piyasa Fiyatı

Piyasa Kapitalizasyonundaki Değişim = Dönem Sonu Piyasa Kapitalizasyonu Dönem Başı Piyasa Kapitalizasyonu

Beklenen Getiri = Dönem Başı Piyasa Kapitalizasyonu x Özkaynak Maliyeti

Hisse Senedi Ihracı = Yeni Hisse Senedi Ihraç Tutarı $x$ Özkaynak Maliyeti

\section{BULGULAR}

BIST 30 endeksinde yer alan firmaların 2012 yılı için hesaplanan Servet Yaratma Endeksi değerleri büyükten küçüğe doğru sıralı şekilde Tablo 1'de sunulmuştur. BIST 30 endeksinde yer alan sadece 6 firmanın Servet Yaratma Endeksi değeri negatif, geriye kalan 24 firmanın Servet Yaratma Endeksi değeri ise pozitif çıkmıştır. Daha önce de belirtildiği üzere, Servet Yaratma Endeksi yatırımcılara hangi firmaların sermaye yatırımlarının fırsat maliyeti üzerinde bir getiri sağladıklarının belirlenmesinde oldukça fayda sağlamakta ve belirli bir zaman periyodunda yatırımcılara olan toplam servet akışını ölçmekte kullanılmaktadır. Ayrıca endeksin hazırlanmasındaki temel kriter, hissedarların ancak yapmış oldukları yatırımın fırsat maliyetini aştığı durumlarda servet elde edebilecekleri fikrine dayanmaktadır. Buradan yola çıkarak bir değerlendirme yapıldığında, Servet Yaratma Endeksi değeri pozitif olan 24 firma için sermaye yatırımlarının, fırsat maliyetinin üzerinde bir getiri sunduğu ve yatırımcılara pozitif bir servet akışı sağladığı söylenebilir. 
Ayrıca söz konusu firmalara yatırım yapan hissedarların, yapmış oldukları yatırımlardan sağladıkları getirinin, fırsat maliyetini aştığı ve bu sayede hissedarlara pozitif bir servet artışı sağladığı ifade edilebilir.

Tablo 1: BIST 30 Endeksinde Yer Alan Firmaların Servet Yaratma Endeksine Göre Sıralaması

\begin{tabular}{|c|c|c|}
\hline Firmalar & Piyasa Kap. Değişim & Servet Yaratma Endeksi Değeri \\
\hline T. Halk Bankası & 7.601.050.000 & 5.778 .093 .133 \\
\hline Bì Mağazalar & 3.769.167.435 & 3.503.592.374 \\
\hline Akbank & 7.051 .544 .000 & 2.137.672.053 \\
\hline Türk Hava Yolları & 2.486 .954 .400 & 1.879.531.318 \\
\hline Sabancı Holding & 3.936.265.648 & 1.810 .566 .697 \\
\hline İş Bankası (C) & 3.841 .403 .890 & 1.152.364.952 \\
\hline Emlak Konut GMYO & 909.187 .500 & 497.855 .421 \\
\hline Koza Madencilik & 743.648 .986 & 484.380 .907 \\
\hline Ereğli Demir Çelik & 865.239 .850 & 471.227 .607 \\
\hline Garanti Bankası & 7.334.258.400 & 465.009 .320 \\
\hline Koza Altın & 817.833 .100 & 421.225 .823 \\
\hline Yapı ve Kredi Bankası & 1.979.899.284 & 384.216 .255 \\
\hline Arçelik & 946.216 .800 & 366.750 .810 \\
\hline Turkcell & 1.969 .506 .000 & 348.770 .225 \\
\hline Vakıflar Bankası & 1.353.030.000 & 337.839 .573 \\
\hline İpek Doğal Enerji & 474.386 .620 & 315.385 .342 \\
\hline Netaş Telekom & 5.297 .833 & 162.907 .661 \\
\hline Tofaş Oto. Fab. & 545.777 .500 & 156.755 .938 \\
\hline İhlas Holding & 233.453 .334 & 156.155 .085 \\
\hline Migros Ticaret & 304.717 .928 & 133.538 .327 \\
\hline Türk Traktör & 320.937 .150 & 131.256 .833 \\
\hline Kardemir (D) & 298.127 .841 & 91.348 .038 \\
\hline Petkim & 326.483 .000 & 75.872 .788 \\
\hline Doğan Holding & 299.110 .700 & 50.406 .268 \\
\hline Asya Katılım Bankası & 302.348 .700 & -40.975 .315 \\
\hline Tüpraş & 1.410.811.689 & -150.213 .228 \\
\hline Koç Holding & 2.165.956.895 & -331.675 .898 \\
\hline Enka İnşaat & 536.129 .000 & -533.566 .898 \\
\hline Şişe Cam & 167.785 .500 & -853.356 .437 \\
\hline Türk Telekom & -46.207 .000 & -1.240 .416 .708 \\
\hline
\end{tabular}

Diğer taraftan Servet Yaratma Endeksi değeri negatif olan 6 firmanın ise tam tersine, sermaye yatırımlarının fırsat maliyetinin üzerinde bir getiri ve yatırımcılara pozitif bir servet akışı sağlamadığı, bu firmalara yapılan yatırımlardan sağlanan getirinin fırsat maliyetinin altında kaldığı söylenebilir. 
Hissedar değeri bakış açısıyla yaklaşıldığında, yatırımcılar Servet Yaratma Endeksi değeri negatif olan hisse senetlerine yatırım yaptıklarında, yatırımlarından sağlayacakları getiri fırsat maliyetinin altında kalacaktır.

Servet Yaratma Endeksi değerlerine göre firmaların sıralaması incelendiğinde, toplamda en fazla servet yaratan ve listede ilk sırada yer alan firmanın T. Halk Bankası'nın olduğu görülmektedir. Diğer firmalarla kıyaslandığında, 5,78 Milyar TL'lik değer ile bu firmanın, toplamda daha yüksek düzeyde servet yarattığı görülmektedir. Sıralamada ikinci sırada yer alan Bї Mağazaları firmasının Servet Yaratma Endeksi değeri 3,50 Milyar TL, üçüncü sırada yer alan Akbank'ın ise 2,14 Milyar TL olmuştur. Türk Telekom Servet Yaratma Endeksi sıralamasında en son sırada yer alırken, onu sırasıyla Şişe Cam, Enka İnşaat, Koç Holding, TÜPRAŞ ve Asya Katılım Bankası izlemektedir.

Servet Yaratma Endeksi değeri pozitif olan 24 firma içerisinde ilk sıralarda yer alan 6 firmanın (T. Halk Bankası, BiM Mağazaları, Akbank, Türk Hava Yolları, Sabancı Holding ve İş Bankası) Servet Yaratma Endeksi değerinin oldukça yüksek olduğu, toplamda diğerlerinden en az iki kat daha fazla bir Servet Yaratma Endeksi değerine sahip olduğu görülmektedir. Ayrıca Servet Yaratma Endeksi değeri en yüksek olan ilk altı firmanın üçünün banka olması dikkat çekmektedir.

\section{SONUÇ VE DEĞERLENDIRME}

Firmaların yaratmış olduğu değer, firma ve firmaların hissedarlarının olduğu kadar o ülkenin ekonomisi açısından da oldukça önem arz etmektedir. Bu nedenle firmanın yaratmış olduğu değerin doğru bir şekilde ölçülmesi son derece önemlidir. Bununla birlikte son yıllarda finansal piyasalarda yaşanan değişim ve gelişmeler geleneksel performans ölçütlerinin değerleme konusunda yetersiz kalmasına neden olmuştur. Kâr maksimizasyonu amacı da yerini hissedar değeri maksimizasyonuna bırakmıştır. Tüm bu gelişmeler nedeniyle finansal piyasalarda yeni finansal performans ölçütlerinin geliştirilmesi zorunluluk haline gelmiştir. Servet Yaratma Endeksi de bu ölçütlerden bir tanesidir. Bu bağlamda bu çalışmanın amacı Türkiye'de daha önce çalışılmamış olan "Servet Yaratma Endeksi" yöntemini kullanarak 2012 yılı için Borsa İstanbul'un lokomotif hisse senetleri olarak adlandırılan BIST 30 firmalarının hissedarlarına değer yaratıp yaratmadıklarını tespit etmek olarak belirlenmiştir. Muhasebe temelli geleneksel performans ölçütleri firmaların tüm kaynaklarının maliyetini dikkate almamaktadır. Servet Yaratma Endeksi ise özkaynağın piyasa değerindeki beklenen değişim ile gerçekleşen değişimi ölçmesi ve değerleme konusuna yatırımcı bakış açısıyla yaklaşması dolayısıyla önemli bir fark yaratmaktadır.

Çalışmadan elde edilen sonuçlar, 2012 yılında BIST 30 endeksinde yer alan firmalardan 6 tanesi hariç kalan 24 firmanın hissedarlarına değer yarattığını göstermektedir. Servet Yaratma Endeksi değeri pozitif olan 24 firmanın 2012 yılı için sermaye yatırımlarının, fırsat maliyetinin üzerinde bir getiri sunduğu, bu firmalara yatırım yapan hissedarların yapmış oldukları yatırımlardan sağladıkları getirinin, hisse senedi maliyetini aştığı ve bu sayede hissedarlara pozitif bir servet artışı sağlandığı söylenebilir. Diğer yandan Servet Yaratma Endeksi değeri negatif olan firmalar için ise tam tersi bir durum söz konusudur. Bununla birlikte elde edilen sonuçları değerlendirirken, Türkiye'deki risksiz faiz oranlarının yüksek olması ve özkaynak maliyetinin hesaplanmasında karşılaşılan güçlükleri de gözardı etmemek gerekir. 
Servet Yaratma Endeksi özkaynak maliyetine duyarlı bir yaklaşımdır. Dolayısıyla özkaynak maliyetinde ortaya çıkacak bir değişiklik firmaların Servet Yaratma Endeksi değerinin de değişmesine neden olacaktır.

Bu çalışmada özkaynak maliyetini hesaplamada Finansal Varlıkları Fiyatlama Modeli kullanılmıştır. Bundan sonra yapılacak çalışmalarda özkaynak maliyeti farklı yöntemlerle de hesaplanarak Servet Yaratma Endeksi değerleri yeniden hesaplanabilir. Ayrıca hisse senedi fiyatlarında yaşanan istikrarsızlıklar Servet Yaratma Endeksi yönteminin en büyük handikabını oluşturmaktadır. Bundan sonra yapılacak çalışmalarda, örneklem dönemi ve firma sayısı arttırılarak çalışma genişletilebileceği gibi, firmaların Servet Yaratma Endeksi değerleri alt sektörler itibariyle hesaplanarak sektörler arası karşılaştırmalar da yapılabilir. Bununla birlikte diğer performans ölçüm yöntemleri ile karşılaştırma yapacak şekilde de bir çalışma yapılabilir. Söz konusu yöntemin diğer değere dayalı performans ölçüm yöntemleriyle birlikte ele alınarak en iyi performansa sahip firmaların tespit edilmesi ve hisse senedi seçimlerinin buna göre yapılmasının daha sağlıklı olacağı düşünülmektedir.

\section{KAYNAKÇA}

Akyüz, Y. (2013), Ekonomik Katma Değer (EVA) ve Pazar Katma Değer (MVA) Analizi: iMKB'de İşlem Gören Seramik İşletmelerinde Bir Uygulama, Süleyman Demirel Üniversitesi İktisadi ve İdari Bilimler Fakültesi Dergisi, Cilt 18, Sayı 2, s.339-356.

Bacidore, J. M., Boquist, J. A., Milbourn, T. T., Thakor, A. V. (1997), The Search for the Best Financial Performance Measure, Financial Analysts Journal, Vol. 53, No. 3, p.11-20.

Bayrakdaroğlu, A. ve Ünlü, U. (2009), Performans Değerlemede EVA ve MVA Ölçütleri: Bu Ölçütler Açısından IMKB ve NYSE'nin Karşılaştırılmalı Analizi, Süleyman Demirel Üniversitesi İktisadi ve İdari Bilimler Fakültesi Dergisi, Cilt. 14, sayı 1, s.287-312.

Chambers, N. (2009), Firma Değerlemesi, İstanbul: Beta Yayınları.

Chandra, P. (2011), Financial Management, Theory and Practice, Published by Tata McGraw-Hill Education Pvt. Ltd. India.

Damodaran, A. (2002), Investment Valuation: Tool and Techniques for Determining The Value of Any Asset, second edition, New York: John Wiley \& Sons Inc.

Ercan, M. K. ve Ban, Ü. (2005), Finansal Yönetim, Ankara: Gazi Kitabevi.

Ertuğrul, M. (2005), Değer Tabanlı Yönetim: Finansal Performans Ölçütlerinin iMKB'de Test Edilmesi, Yayınlanmamış Doktora Tezi, Eskişehir: Anadolu Üniversitesi Sosyal Bilimler Enstitüsü.

Görke, A. (2011), Value-Based Management at DAX-listed Companies, Grin Verlag, Germany.

Gürbüz, A. O. ve Ergincan, Y. (2004), Şirket Değerlemesi: Klasik ve Modern Yaklaşımlar, Yayın No: 119, İstanbul: Literatür Yayıncılık.

Kara, H. (2005), Katma Değer Yaratmaya Dayalı Finansal Performans Ölçütü Olarak EVA (Economic Value Added) IMKB Şirketleri Üzerine Bir Uygulama, SPK Yayınları, Yayın No 184, Ankara.

Lee, S. and Kim, W. G. (2009), EVA, Refined EVA, MVA, or Traditional Performance Measures for the Hospitality Industry?, International Journal of Hospitality Management, Vol. 28, No. 3, p.439-455.

Ottoson, E. and Weissenrieder F. (1999), CVA: Cash Value Added- A New Method For Measuring Financial Performance, Gothenburg Studies in Financial Economics Working Paper.

Öztürk, M. B. (2004), Finansal Performansın Ölçülmesinde Alternatif Bir Yöntem: Ekonomik Katma Değer, Atatürk Üniversitesi İktisadı ve İdari Bilimler Fakültesi Dergisi, Cilt 18, Sayı 3, s.351-368.

Sakarya, Ş. (2008), Hissedar Değeri ve Hesaplanması Üzerine Bir Uygulama, Muhasebe ve Finansman Dergisi, Cilt 40, s.175-184. 
Stern, E. And Pigott, J. (2002), Perspectives on Business: Introduction to the Wealth Added Index (WAI), Stern Stewart \& Co. London.

Stewart III., Bennett, G (1991), The EVA Management Guide: The Quest for Value, Harper Business Publishers, 1991, New York.

Şamiloğlu, F. (2004), Faaliyet Kârı, Artık Gelir ve Ekonomik Katma Değer: Hangisi Hisse Senedi Getirileri Ile Daha Yüksek illişkilidir? İstanbul Üniversitesi İşletme Fakültesi Dergisi, Cilt 33, Sayı 1, s. 7-20.

Ünlü, U (2014-Kabul), Yatıımın Nakit Akım Karlıı̆̆ı (CFROI) ve Nakit Katma Değer (CVA) Yöntemi: Borsa İstanbul'da İşlem Gören Çimento Firmaları Üzerine Ampirik Bir Uygulama, Eskişehir Osmangazi Üniversitesi iïBF Dergisi, Cilt 9-2.

Ünlü, U ve O. Saygın, (2014), Arındırılmış Ekonomik Katma Değer (REVA) Yöntemiyle Performans Ölçümü: Turizm Sektörü Uygulaması, Muhasebe ve Finansman Dergisi, Cilt 63, s.139-150.

Venanzi, D. (2012), Financial Performance Measures and Value Creation: the State of the Art, Springer.

Wealth Added Scorecard (2005), https://www.set.or.th/th/news/download/files/WAI2005-SET1.pdf (Erişim Tarihi: 08.07.2014)

YıImaz, T. ve Bastı, E. (2013), İmalat Sanayi Şirketlerinin Ekonomik Katma Değer (EVA) ve Piyasa Katma Değerine (MVA) Dayalı Performans Analizi: IMKB Örneği, Yönetim ve Ekonomi Araştırmaları Dergisi, Sayı 21, s.82-105. 